\title{
Simvastatin inhibits cell growth and induces apoptosis and G0/G1 cell cycle arrest in hepatic cancer cells
}

\author{
BORNA RELJA, FRANK MEDER, KERSTIN WILHELM, DIRK HENRICH, \\ INGO MARZI and MARK LEHNERT \\ Department of Trauma Surgery, Johann Wolfgang Goethe University, Frankfurt am Main, Germany
}

Received May 31, 2010; Accepted July 27, 2010

DOI: 10.3892/ijmm_00000520

\begin{abstract}
Hepatocellular carcinoma (HCC) is one of major health concerns worldwide and one of leading causes of cancer death after lung and gastric cancers. Simvastatin is a cholesterol-lowering drug which inhibits 3-hydroxy-3-methylglutarylcoenzyme CoA (HMG-CoA) reductase. Simvastatin exhibits numerous pleiotropic effects including anti-cancer activity. Yet, the anticancer effects in HCC remain poorly characterized. Therefore, in this study, we investigated the effects of simvastatin on tumor cell growth, apoptosis and cell cycle. HepG2 and Huh7 cell lines were treated with simvastatin (32 and $64 \mu \mathrm{M}$ ) for different time periods. Tumor cell growth was assessed using MTT assay. Apoptosis and cell cycle analysis were also evaluated. Analysis of cell cycle proteins involved in simvastatin-induced manipulation was performed by Western blot and quantitative RT-PCR analyses. Simvastatin induced a reduction of tumor cell growth. In both cell lines, simvastatin induced apoptosis and impaired cell cycle progression as depicted by the greater rates of G0/G1-phase cells than the rates of S-phase cells. Protein expression levels of cell cycle regulating proteins CDK1, CDK2, CDK4, cyclin D1, cyclin E, p19 and p27 were markedly altered by simvastatin. Moreover, $C D C 2$, $C C N D 1$ and $C D C N 2 D$ mRNA expressions were also altered by drug treatment. Collectively, these results suggest that simvastatin induces apoptosis in tumor cells and its anti-proliferative activity was accompanied by inhibition of cyclin-dependent kinases and cyclins, whereas CDK inhibitors p19 and p27 were enhanced. These results may provide novel insights into simvastatin tumor-suppressive action.
\end{abstract}

\section{Introduction}

Hepatocellular carcinoma (HCC), one of most common malignancies and causes of cancer death worldwide, is

Correspondence to: Dr Borna Relja, Department of Trauma, Hand and Reconstructive Surgery, Hospitals of the Goethe-University, D-60590 Frankfurt am Main, Germany

E-mail: info@bornarelja.com

Key words: liver, cancer, simvastatin, cell cycle, apoptosis characterized by a poor prognosis and recurrence within a short time (1-5). HCC is frequently derived from chronic liver diseases, such as alcoholic liver disease or viral hepatitis, with increasing incidence in Europe, the United States and in certain areas in Asia (6,7). Radical therapies, such as resection, liver transplantation or percutaneous ablation are applicable only for early or small HCC. At an advanced stage, in selected patients transarterial chemoembolization (TACE) is possible, but systemic chemotherapy often remains the only alternative therapy for the majority of patients, despite its modest anti-tumor capacity against HCC (8-11). Therefore, there is a need for alternative strategies focusing on HCC.

Simvastatin, one of the 3-hydroxy-3-methylglutaryl coenzyme A (HMG-CoA) reductase inhibitors, is currently widely used safe and well tolerated therapeutic agent for treating hypercholesterolemia, atherosclerosis, coronary heart disease and stroke (12). Emerging research suggests that simvastatin exerts despite of its effective cholesterol lowering role, antiproliferative, proapoptotic and anti-invasive effects in cancer cells $(13,14)$. In several human malignancies, including breast, colon, prostate cancer and melanoma, simvastatin had selective anticancer effects, which were attributed to cell cycle arrest in the $\mathrm{G} 1$ and $\mathrm{G} 2 / \mathrm{M}$ phases, thereby inhibiting cell proliferation as well as apoptotic and necrotic cell death induction (14-18). However, the efficacy and the molecular mechanism of simvastatin on HCC progression have yet to be clarified.

Given the need for alternative therapeutic strategies, these findings in parallel with limited knowledge about simvastatin's influence on HCC prompted us to evaluate its potential therapeutic options for HCC. The objective of this study was to determine i) whether simvastatin exerts anticancer effects in HepG2 and Huh7 and ii) the mechanism by which simvastatin exerts these effects. We evaluated reduced tumor cell growth and enhanced tumor cell death of both, apoptotic and necrotic cells after simvastatin treatment. Cell cycle analyses by Western blot and qRT-PCT revealed simvastatin-induced cell cycle arrest in G0/G1 and the cell cycle regulating proteins involved in these modifications.

\section{Materials and methods}

Cell cultures. Human HCC cell lines HepG2 and Huh7 were purchased from Cell Line Services (Heidelberg, Germany). Tumor cells were maintained at $37^{\circ} \mathrm{C}$ under $5 \% \mathrm{CO}_{2}$ in 
RPMI-1640 medium (Seromed, Berlin, Germany) supplemented with $10 \%$ heat-inactivated fetal calf serum (FCS), $100 \mathrm{IU} / \mathrm{ml}$ penicillin and $100 \mu \mathrm{g} / \mathrm{ml}$ streptomycin (Gibco, Karlsruhe, Germany) and $20 \mathrm{mM}$ HEPES buffer (Sigma, Steinheim, Germany).

Drug treatment. Simvastatin was obtained from Calbiochem (Darmstadt, Germany) and activated prior to the experiments by alkaline hydrolysis of the lactone moiety according to the manufacturer's protocol. Tumor cells were treated 24, 48 and $72 \mathrm{~h}$ with simvastatin (32 and $64 \mu \mathrm{M})$ or with vehicle (ctrl) with fresh changes of culture medium and simvastatin after $48 \mathrm{~h}$.

Tumor cell growth. Cell proliferation kit I (3-(4,5-dimethylthiazol-2-yl)-2,5-diphenyltetrazolium bromide, MTT; Roche Diagnostics, Penzberg, Germany) was used to evaluate MTTreducing activity of the cellular mitochondria. HepG2 and Huh7 cells $\left(100 \mu 1,1 \times 10^{4} / \mathrm{ml}\right)$ were seeded onto 96-well tissue culture plates and incubated with simvastatin or vehicle as described above to monitor time- and dose-response. Twenty-four hours before the evaluation of each time-point, MTT $(0.5 \mathrm{mg} / \mathrm{ml})$ was added to each well, and the cells were incubated for $4 \mathrm{~h}$ at $37^{\circ} \mathrm{C}$. Thereafter, cells were lysed in a solubilization solution containing $10 \%$ sodium dodecyl sulphate $(\mathrm{SDS})$ in $0.01 \mathrm{M}$ hydrogen chloride $(\mathrm{HCl})$ and incubated overnight at $37^{\circ} \mathrm{C}$ in $5 \% \mathrm{CO}_{2}$. The following day the absorbance of each well was measured with a multimode microplate reader (Infinite M200; Tecan, Crailsheim, Germany) at $550 \mathrm{~nm}$. Each experiment was performed in triplicate. After substracting the background absorbance, results were expressed as mean cell number.

Measurement of apoptosis. After treatment with simvastatin or vehicle (ctrl), HepG2 and Huh7 cells were incubated with propidium iodide (PI) and Annexin V-conjugated fluorescein isothiocyanate (FITC) from an Annexin V-FITC Apoptosis detection kit 1 (Becton Dickinson) according to manufacturer's instructions. Annexin V-FITC/PI binding was evaluated by flow cytometry with a FACScan flow cytometer (excitation wavelength $488 \mathrm{~nm}$, emission wavelength $530 \mathrm{~nm}$; Becton Dickinson). The population of PI-negative/Annexin V-positive cells was related to early apoptosis, and that of PI-positive/ Annexin V-positive cells was related to late apoptosis/ secondary necrosis.

Cell cycle analysis. HepG2 and Huh7 cells were grown to 70\% confluency and then treated with simvastatin or vehicle (ctrl). Cell cycle analyses were carried out after $48 \mathrm{~h}$. Tumor cells were stained with propidium iodide using a Cycle Test Plus DNA reagent kit (Becton Dickinson) and then subjected to flow cytometry with a FACScan flow cytometer (Becton Dickinson). From each sample 10,000 cells were measured. Data acquisition was carried out using Cell-Quest software and cell cycle distribution calculated using ModFit software (Becton Dickinson). The number of gated cells in G1, G2/M or S-phase was presented as percentage $(\%)$. Each experiment was performed in triplicate.

Western blotting. Cell cycle regulating proteins were analyzed in Western blotting. Total cdk1, cdk2, cdk4, cyclin D1, cyclin E, p19 and p27 contents in HepG2 and Huh7 cells were evaluated by Western blot analysis using mouse anti-Cdk1 (clone 1), anti-Cdk2 (clone 55), anti-Cdk4 (clone 97), antihuman Cyclin D1 (clone DCS-6), anti-human Cyclin E (HE12), anti-p19 [Skp1] (clone 52) and anti-p27 [Kip1] (clone G173-524; all BD Biosciences, Heidelberg, Germany). Tumor cell lysates (50 $\mu \mathrm{g}$ protein) were separated by electrophoresis on $12 \%$ polyacrylamide SDS gels and transferred to nitrocellulose membranes (Amersham-Buchler, Braunschweig, Germany). Determination of $B$-actin with antiB-actin antibody (clone AC-15; Sigma, Taufkirchen, Germany) served as loading control. Blots were blocked (10\% non-fat dry milk in $1 \mathrm{mM}$ Tris, $150 \mathrm{mM} \mathrm{NaCl}, \mathrm{pH} \mathrm{7.4)}$ for $1 \mathrm{~h}$, incubated $1 \mathrm{~h}$ at RT with primary antibody (diluted according to manufacturer's instructions in blocking buffer with $0.5 \%$ Tween-20 and $0.5 \%$ bovine serum albumin) and then incubated $1 \mathrm{~h}$ with horseradish peroxidase-conjugated secondary antibody (HRP-conjugated goat anti-mouse IgG, Upstate Biotehcnology, Lake Placid, NY, USA) diluted 1:5000 in blocking buffer with $0.5 \%$ Tween-20 and $0.5 \%$ bovine serum albumin at RT. Proteins were detected with ECL $^{\text {тм }}$ Western blot detection reagents (GE Healthcare, Munich, Germany) and visualized after exposure on X-ray film (Hyperfilm ${ }^{\mathrm{TM}}$ ECTM, Amersham, Freiburg, Germany). The film was digitized, and the integrated density of individual bands was determined using the software Multianalyst (Bio-Rad, Munich, Germany). By densitometric measurements using the same software the amount of protein expression was normalized to $\beta$-actin.

Ribonucleic acid (RNA) isolation, quantitative reversetranscription-polymerase chain reaction $(R T-P C R)$. Total RNA was isolated using the RNeasy-system (Qiagen, Hilden, Germany) according to the manufacturer's instructions. The RNA was stored immediately at $-80^{\circ} \mathrm{C}$. Quality and amount of the RNA were determined photometrically using the NanoDrop ND-1000 device (NanoDrop Technologies, Wilmington, DE, USA).

RNA was subsequently used for qRT-PCR. In brief, $100 \mathrm{ng}$ of total RNA was reversely transcribed using the Affinity script QPCR-cDNA synthesis kit (Stratagene, La Jolla, CA, USA) following the manufacturer's instructions. To determine the mRNA expression of Cdk1 (CDC2), Cyclin D1 (CCND1) and p19 (CDKN2D), qRT-PCR was carried out on a Stratagene MX3005p QPCR system (Stratagene) using gene-specific primers for human CDC2 (NM 001786, UniGene no. Hs.334562, Cat no. PPH00116B), human CCND1 (NM 053056, UniGene no. Hs.523852, Cat no. PPH00128E) and human CDKN2D (NM 001800, UniGene no. Hs.435051, Cat no. PPH00210B) purchased from SABiosciences (SuperArray, Frederick, MD, USA). As reference gene, the expression of GAPDH with human GAPDH (NM 002046, UniGene no. Hs.592355, Cat no. PPH00150E; SABiosciences) was measured. Sequences of these primers are not available. PCR reaction was set up with 1X RT2 SYBR Green/ Rox qPCR Master mix (SABiosciences) in a $25 \mu 1$ volume according to manufacturer's instructions. A two-step amplification protocol consisting of initial denaturation at $95^{\circ} \mathrm{C}$ for $10 \mathrm{~min}$ followed by 40 cycles with $15 \mathrm{sec}$ denaturation at $95^{\circ} \mathrm{C}$ and $60 \mathrm{sec}$ annealing/extension at $60^{\circ} \mathrm{C}$ 
A

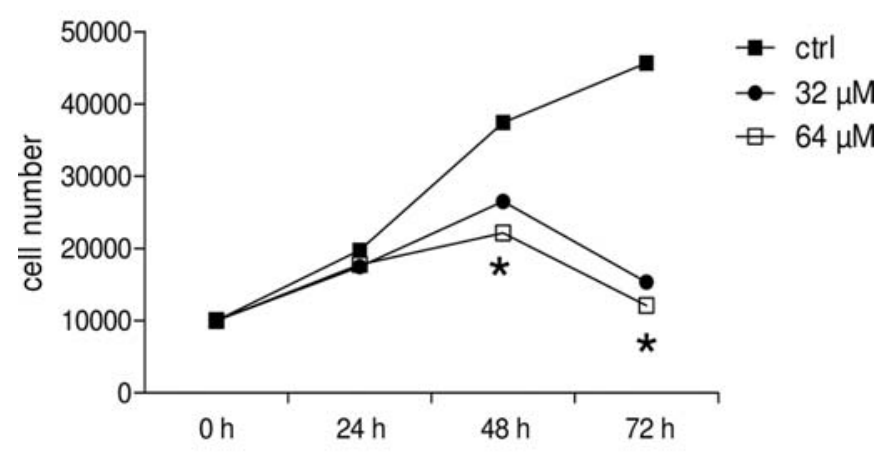

B

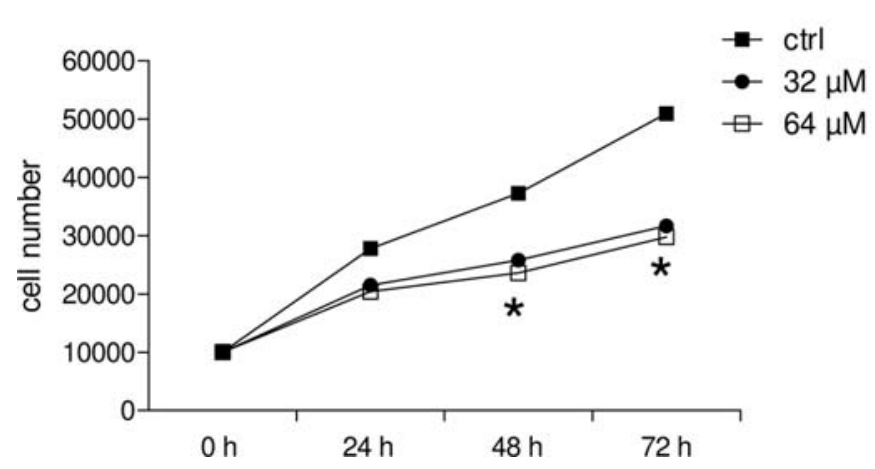

Figure 1. Effects of simvastatin on the cell growth. HepG2 and Huh7 cells were treated with simvastatin $(32$ and $64 \mu \mathrm{M})$ for 24,48 and $72 \mathrm{~h}$ or vehicle (ctrl). Then, cells were placed on a 96-well culture plate and cell proliferation was assessed using the 3-(4,5-dimethylthiazol-2-yl)-2,5diphenyltetrazolium bromide (MTT) dye reduction assay. The assays were carried out in triplicate and data are given as mean \pm SEM. Representative figure from one out of three experiments is shown $\left({ }^{*} \mathrm{p}<0.05 \mathrm{vs}\right.$. ctrl $)$.

was chosen. A melting-curve analysis was applied to control the specificity of amplification products. The amount of target mRNA in each sample was normalized to the amount of GAPDH mRNA. We conducted three replicates for the arrays and had three replicates of the individual genes in the PCR. The relative mRNA expression of target genes after normalization to GAPDH is presented.

Statistical analysis. All experiments were performed 3-6 times. Differences between groups were determined by WilcoxonMann-Whitney U-test. $\mathrm{p}<0.05$ was considered significant. Data are given as mean \pm standard error of the mean (SEM).

\section{Results}

Simvastatin inhibits tumor cell growth. Tumor cell growth analysis revealed rapid cell growth of both cell lines HepG2 and Huh7. Fig. 1 demonstrates that both doses of simvastatin (32 and $64 \mu \mathrm{M}$ ) had a significant inhibitory effect on tumor cell growth as compared to controls (ctrl, $\mathrm{p}<0.05)$. This effect was time-dependent, since a simvastatin pre-treatment for $48 \mathrm{~h}$ or $72 \mathrm{~h}$ significantly reduced cell growth as compared to $24 \mathrm{~h}$ pre-incubation with simvastatin $(\mathrm{p}<0.05)$.
A

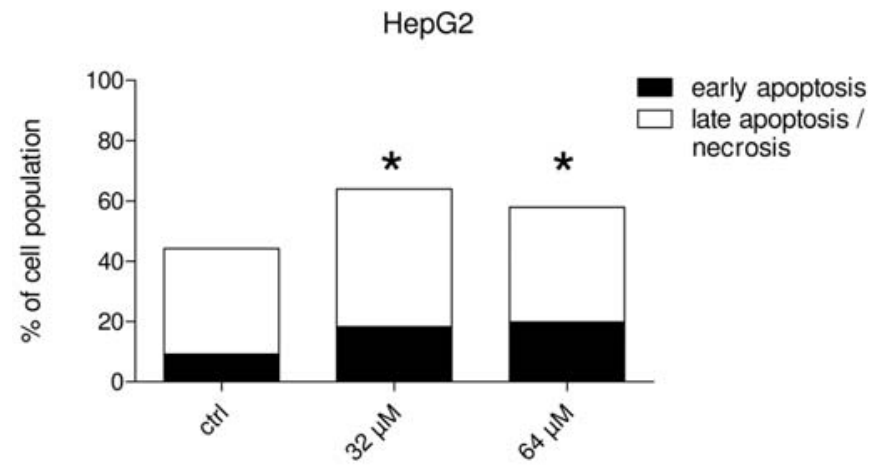

B

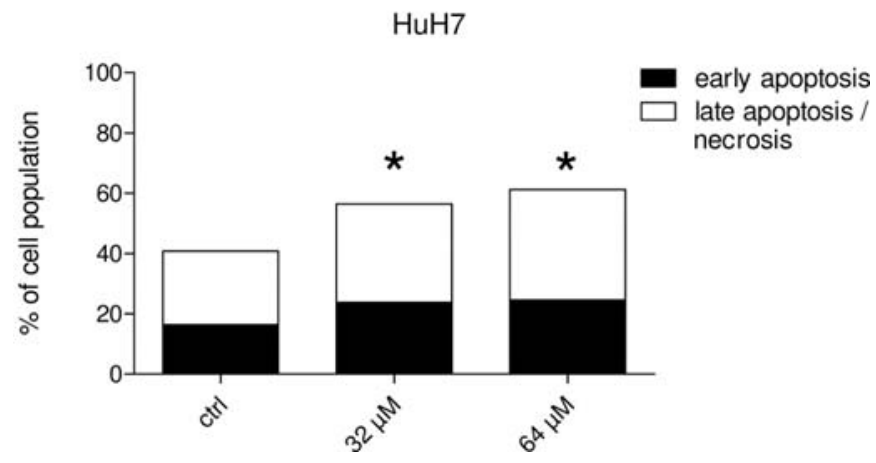

Figure 2. Simvastatin induces cell death by apoptosis in HepG2 and Huh7 cells. The mechanism of cell death in HepG2 and Huh7 cells was determined $48 \mathrm{~h}$ after 32 or $64 \mu \mathrm{M}$ simvastatin exposure by staining cells with Annexin V-FITC and propidium iodide (PI). PI-negative/Annexin V-positive cells were related to early apoptosis, and PI-positive/Annexin V-positive cells were related to late apoptosis/secondary necrosis. The percentage of early apoptotic and late apoptotic/necrotic cells was averaged from three independent experiments $\left({ }^{*} \mathrm{p}<0.05 \mathrm{vs}\right.$. $\left.\mathrm{ctrl}\right)$.

Induction of apoptosis in HepG2 and Huh7 cells by simvastatin. To study the effect of simvastatin on cell survival HepG2 and Huh7 cells were treated with 32 or $64 \mu \mathrm{M}$ for $48 \mathrm{~h}$. Fig. 2 shows cell death rates of treated versus vehicle-treated cells (ctrl). In HepG2 cells, early apoptosis markedly increased by simvastatin treatment from $9.2 \%$ in non-treated ctrl cells to $18.2 \%$ (32 $\mu \mathrm{M}$ simvastatin) and 19.8\% $(64 \mu \mathrm{M})$, respectively $(\mathrm{p}<0.05)$. Late apoptosis/necrosis rates increased from $35.0 \%$ in ctrl cells to $56.9 \%$ (32 $\mu \mathrm{M}$ simvastatin) and $48.0 \%(64 \mu \mathrm{M})$, respectively $(\mathrm{p}<0.05)$. In Huh7 cells, early apoptosis rates increased from $16.3 \%$ in non-treated ctrl cells, to $23.8 \%$ and $24.5 \%$ in simvastatin pre-treated cells $(32 \mu \mathrm{M}$ and $64 \mu \mathrm{M}$, respectively). Late apoptosis/necrosis rates increased markedly from $24.7 \%$ in ctrl cells to $32.8 \%$ (32 $\mu \mathrm{M}$ simvastatin) and $36.8 \%(64 \mu \mathrm{M})$, respectively $(\mathrm{p}<0.05)$.

Simvastatin-induced cell cycle arrest in G1. To elucidate the mechanism of simvastatin-induced tumor cell growth inhibition, we examined the effect of simvastatin on cell cycle distribution by flow cytometry. As shown in Fig. 3, concomitant with the inhibitory effect on tumor cell growth, simvastatin treatment induced a strong G1 phase arrest after $48 \mathrm{~h}$ treatment. Cell populations in the G0/G1, S and G2/M 
A

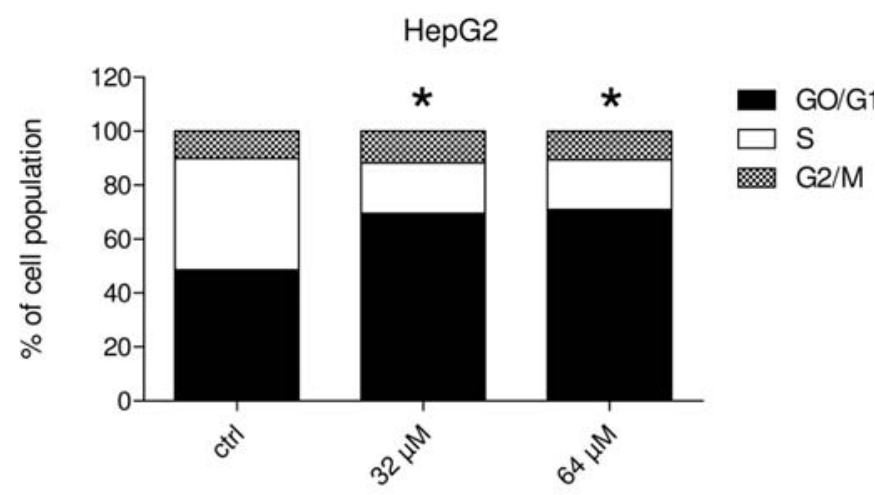

B

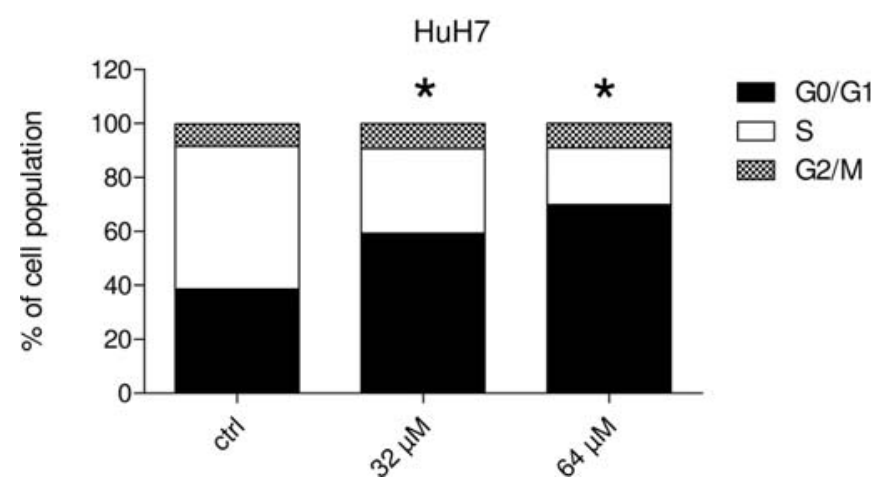

Figure 3. Simvastatin effects on cell cycle of HepG2 and Huh7. Cells were treated with simvastatin $(32$ or $64 \mu \mathrm{M})$ or vehicle (ctrl). Distribution of cell cycle fractions (G0/G1, S and G2/M phase) was determined using propidium iodide staining as described in Materials and methods. Percentages of populations in each cell cycle phase were averaged from three independent experiments $\left(\mathrm{G} 0 / \mathrm{G} 1\right.$ cell cycle arrest $={ }^{*} \mathrm{p}<0.05 \mathrm{vs}$. ctrl $)$.

phases were $44,45.8$ and $10.2 \%$, respectively, in ctrl HepG2 cells, and 38.6, 53.1 and 8.3\%, respectively, in Huh7 ctrl cells. After $48 \mathrm{~h}$ incubation with $32 \mu \mathrm{M}$ or $64 \mu \mathrm{M}$ simvastatin, the $\mathrm{S}$ phase population was largely reduced to $17.8 \%$ and $18.1 \%$ in HepG2 and $30.4 \%$ and $20.1 \%$ in Huh7 cells, respectively ( $\mathrm{p}<0.01 \mathrm{vs}$. ctrl). After $48 \mathrm{~h}$ incubation with $32 \mu \mathrm{M}$ or $64 \mu \mathrm{M}$ simvastatin this reduction in the $\mathrm{S}$ phase was accompanied by a concomitant increase in the G0/G1 phase cell populations to $70 \%$ and $70.9 \%$ in HepG2 and $59.6 \%$ and $70 \%$ in Huh7 cells, respectively ( $\mathrm{p}<0.01$ vs. ctrl).

As another index for $\mathrm{G} 1$ phase arrest, we measured the expression levels of cyclin-dependent kinases CDK1, CDK2, CDK4, of cyclins D1 and E, and of cyclin-dependent kinase inhibitors p19 and p27, because the cyclin D/E-CDK2/4 complexes are the primary regulators of the G1/S phase reconstruction points. As representatively demonstrated in Fig. 4, HepG2 cells exposed to simvastatin treatment for 48 or $72 \mathrm{~h}$ exhibited downregulation of CDK1, CDK2, CDK4 and cyclins D1 and E as compared to ctrl tumor cells. Relative expression of cyclin-dependent kinase inhibitors p19 and p27 enhanced with simvastatin treatment for 24,48 and $72 \mathrm{~h}$ as compared to ctrl tumor cells. These findings coincide with the simvastatin-induced cell cycle arrest in the G0/G1 phase.

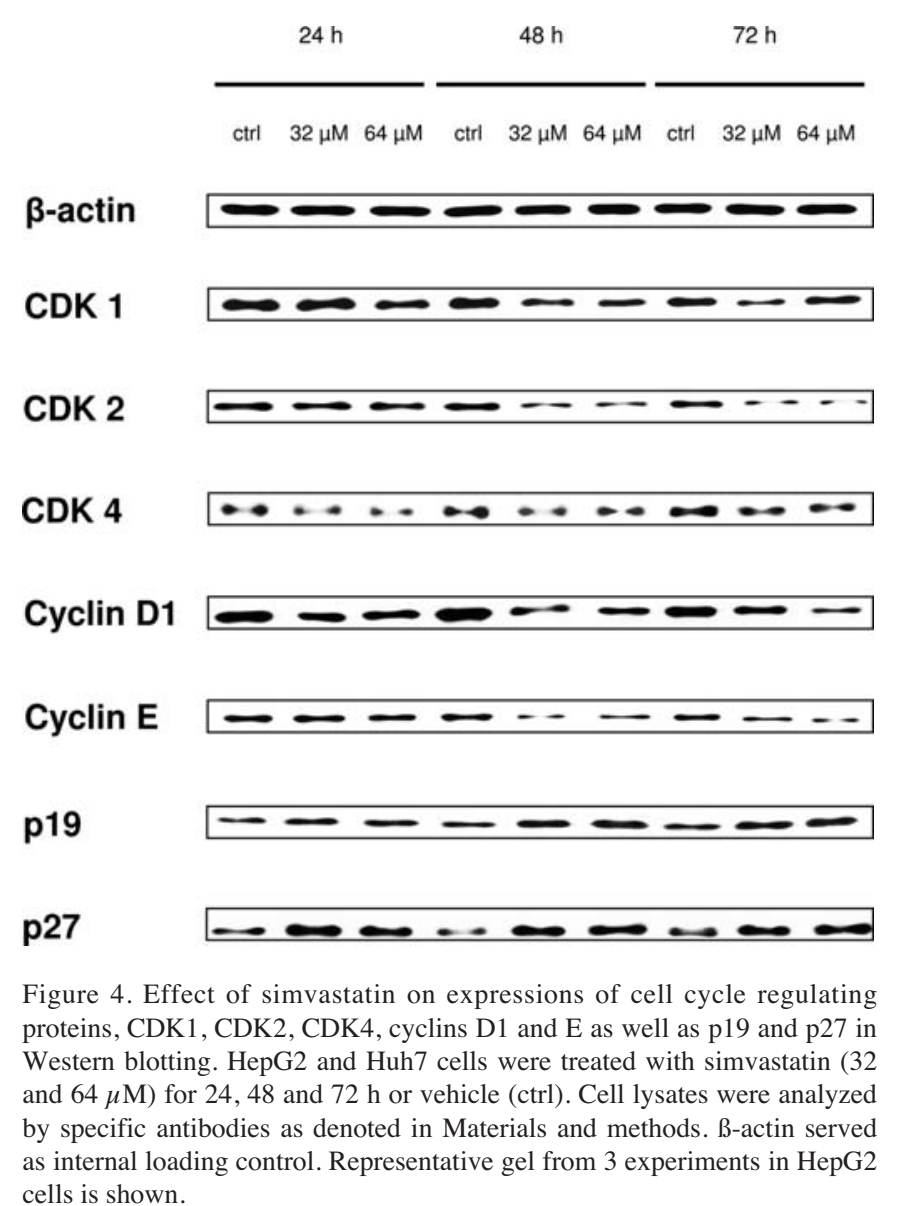
cells is shown.

Differential gene expression in simvastatin treated tumor cells. To analyze target genes responsive to the effects of simvastatin in HCC, we examined changes in CDC2 (CDK1), $C C N D 1$ (cyclin D1) and CDKN2D (p19) gene expression in HepG2 and Huh7 cells after treatment with simvastatin. The qRT-PCR showed evident expression of $C D C 2$ and $C C N D 1$ in non-treated control cells, which was significantly reduced after simvastatin treatment for 24,48 or $72 \mathrm{~h}$ (Fig. 5, representative for HepG2). Simvastatin up-regulated gene expression of the cyclin-dependent kinase inhibitor p19 as compared to ctrl (Fig. 5).

\section{Discussion}

The present study showed that simvastatin effectively suppressed tumor cell growth and survival of tumor HepG2 and Huh7 cells. These effects were associated with reduced expression of cyclin-dependent kinases (CDKs) and cyclins, whereas CDK inhibitors p19 and p27 were enhanced, suggesting that simvastatin's cell cycle-suppressive action is involved in its anti-cancer properties.

In cancer cells, apoptosis is deregulated and resistance to apoptosis has been correlated with increased metastatic potential in animal models $(19,20)$. Many naturally occurring as well as synthetic drugs comprise apoptosis in their anticancer activity (21). Thus, it is likely that simvastatin acting through apoptotic activation may counteract metastasis, recurrence and progression of HCC. 

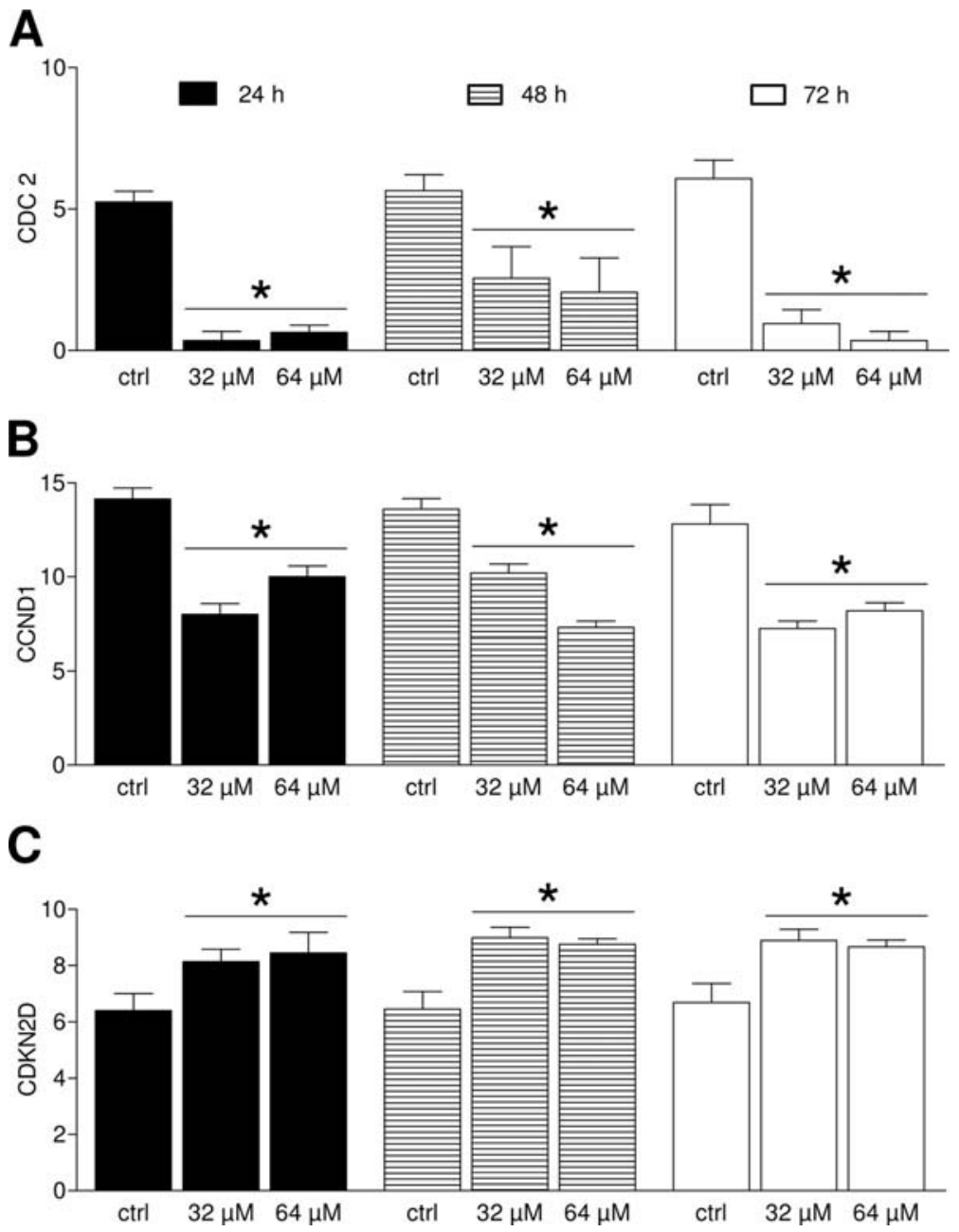

Figure 5. Effects of simvastatin on gene expressions of $C D C 2$ (CDK1), $C C N D 1$ (cyclin D1) and $C D K N 2 D$ (p19). Quantitative real-time (qRT)-PCR analyses of the three cell cycle regulators 24,48 and $72 \mathrm{~h}$ after treatment of HepG2 cells with 32 or $64 \mu \mathrm{M}$ simvastatin or vehicle (ctrl) is shown. The relative mRNA expressions of target genes after normalization to GAPDH as described in Materials and methods are represented. Data are given as mean \pm SEM. Representative figure from one out of three similar experiments is shown ( ${ }^{*} \mathrm{p}<0.05 \mathrm{vs}$. ctrl $)$.

Statins are known to alter several cellular mechanisms resulting in apoptosis, reduced tumor cell growth as well as angiogenesis and impaired metastatic process (22). Although simvastatin has been demonstrated to exert in vitro and in vivo anti-tumor effects on various cancer types including human myeloma cells, breast cancer, leukemia cells, prostate cancer and malignant glioblastoma cells by inhibiting tumor cell growth and inducing apoptosis, the anti-tumor effects of simvastatin on hepatocellular carcinoma have not yet been investigated in depth (23-27). The present in vitro model reveals that simvastatin is effective in inhibiting the cell growth and also induces apoptosis in human carcinoma cell lines HepG2 and Huh7. Interestingly, the HMG-CoA reductase inhibitors fluvastatin and pravastatin inhited proliferation and induced apoptosis in hepatocellular carcinoma cells but also demonstrated anti-cancer effects in rat HCC in vivo models by inhibiting cancer progression and improving survival (28-30). As statins are commonly used drugs for treatment of hypercholesterolemia, the cancer risk and recurrence among statin users versus non-users is gaining increasing interest. Recent clinical data showed that pravastatin improved survival of patients with advanced HCC compared with non-users $(31,32)$. Combined therapy of leucovorin with simvastatin demonstrated beneficial effects in metastatic colorectal cancer patients (33). Therefore, a multidrug therapy including simvastatin could be useful in HCC therapy.

Eukaryotic cell cycle progression is regulated by CDKs, and cyclin-dependent kinase inhibitors whose activity is highly controlled and coordinated by their association with cyclins (34). Cyclin-dependent kinase inhibitors bind with active CDK-cyclin complexes and thereby exert tumor-suppressive role that downregulates the cell cycle progression $(35,36)$. Analyses of human cancers revealed that cell cycle regulators are frequently mutated in most common malignancies $(37,38)$. Therefore, control of the cell cycle progression in malignant cells may deliver an effective strategy for the control of tumor cell growth. In the current study, simvastatin induced a G0/G1 arrest of the cell cycle progression in HepG2 and Huh7 cell lines, indicating an additional mechanism by which simvastatin may impact the proliferation of HCC cells. In several human malignancies including breast, colon, prostate cancer and melanoma, simvastatin had anti-cancer effects, which were indeed attributed to cell cycle arrest in the G1 and G2/M phases (14-18). Nevertheless, the efficacy and the molecular mechanism of simvastatin on HCC progression have yet to be clarified. 
To analyze the underlying biological mechanisms in simvastatin-induced $\mathrm{HCC}$ cell cycle arrest in $\mathrm{G} 0 / \mathrm{G} 1$, protein and gene expressions of CDKs, cyclins and CDK-inhibitors, p19 and p27 were evaluated. Simvastatin-induced reduction of the cell population in the $\mathrm{S}$ phase and G0/G1 cell cycle arrest were associated with a marked reduction in the protein levels of CDK1, CDK2, CDK4, cyclins D1 and E. Moreover, gene expressions of CDK1 and cyclin D1 were also reduced markedly after simvastatin treatment. Furthermore, we suggest that simvastatin-induced G1 arrest in cell cycle progression in HepG2 and Huh7 cells is thought to be mediated via an upregulation of p19 and p27 proteins, which was accompanied by enhanced p19 gene expression. In line with these results, another group has shown that enhancement in p19 or p27 in other cancer types by statins induced a cell cycle arrest $(39,40)$. Recently, induction of p19 in Ataxia Telangiectasia Mutatedknockout mice resulted in cell cycle arrest, apoptosis and abrogated hepatocarcinogenesis in a long-term in vivo model (41). Simvastatin has the potential to enhance p27 and induce cell cycle arrest $(18,42)$. However, its role in HCC has not been described previously within this context. Our study demonstrated that simvastatin-induced cell cycle arrest in G0/G1 by down-regulating CDKs and cyclins and enhancing p19 and p27 (Figs. 3-5). Based on our results and reports of others, we conclude that HCC development might be caused by altered expression of cell cycle regulators. However, simvastatin-induced cell cycle arrest was accompanied by apoptosis, necrosis and reduced cell proliferation.

In conclusion, CDK1, cyclin D1 and p19 play a decisive role in the carcinogenesis of $\mathrm{HCC}$, since their up-regulation by simvastatin may be associated with reduced tumor cell growth and cell death. Hence, this study demonstrates the anti-carcinogenic and protective role of simvastatin in our HCC model and suggests that simvastatin may be a promising candidate for therapeutic intervention.

\section{Acknowledgements}

We thank Minhong Wang for outstanding technical assistance.

\section{References}

1. Jemal A, Siegel R, Ward E, Hao Y, Xu J and Thun MJ: Cancer statistics, 2009. CA Cancer J Clin 59: 225-249, 2009.

2. Ferlay J, Autier P, Boniol M, Heanue M, Colombet M and Boyle P: Estimates of the cancer incidence and mortality in Europe in 2006. Ann Oncol 18: 581-592, 2007.

3. Kamangar F, Dores GM and Anderson WF: Patterns of cancer incidence, mortality, and prevalence across five continents: defining priorities to reduce cancer disparities in different geographic regions of the world. J Clin Oncol 24: 2137-2150, 2006 .

4. Roayaie S, Schwartz JD, Sung MW, et al: Recurrence of hepatocellular carcinoma after liver transplant: patterns and prognosis. Liver Transpl 10: 534-540, 2004.

5. Morris-Stiff G, Gomez D, de Liguori CN and Prasad KR: Surgical management of hepatocellular carcinoma: is the jury still out? Surg Oncol 18: 298-321, 2009.

6. Llovet JM, Burroughs A and Bruix J: Hepatocellular carcinoma. Lancet 362: 1907-1917, 2003.

7. El-Serag HB, Mason AC and Key C: Trends in survival of patients with hepatocellular carcinoma between 1977 and 1996 in the United States. Hepatology 33: 62-65, 2001.

8. Yuen MF, Cheng CC, Lauder IJ, Lam SK, Ooi CG and Lai CL: Early detection of hepatocellular carcinoma increases the chance of treatment: Hong Kong experience. Hepatology 31: 330-335, 2000 .
9. Lee HS, Kim KM, Yoon JH, et al: Therapeutic efficacy of transcatheter arterial chemoembolization as compared with hepatic resection in hepatocellular carcinoma patients with compensated liver function in a hepatitis B virus-endemic area: a prospective cohort study. J Clin Oncol 20: 4459-4465, 2002.

10. Asnacios A, Fartoux L, Romano O, et al: Gemcitabine plus oxaliplatin (GEMOX) combined with cetuximab in patients with progressive advanced stage hepatocellular carcinoma: results of a multicenter phase 2 study. Cancer 112: 2733-2739, 2008.

11. Chou YY, Cheng AL and Hsu HC: Expression of P-glycoprotein and p53 in advanced hepatocellular carcinoma treated by single agent chemotherapy: clinical correlation. J Gastroenterol Hepatol 12: 569-575, 1997.

12. Goldstein JL and Brown MS: Regulation of the mevalonate pathway. Nature 343: 425-430, 1990.

13. Newman A, Clutterbuck RD, Powles RL and Millar JL: Selective inhibition of primary acute myeloid leukaemia cell growth by simvastatin. Leukemia 8: 2023-2029, 1994.

14. Ghosh-Choudhury N, Mandal CC, Ghosh-Choudhury N and Ghosh-Choudhury G: Simvastatin induces derepression of PTEN expression via NFkappaB to inhibit breast cancer cell growth. Cell Signal 22: 749-758, 2010.

15. Cho SJ, Kim JS, Kim JM, Lee JY, Jung HC and Song IS: Simvastatin induces apoptosis in human colon cancer cells and in tumor xenografts, and attenuates colitis-associated colon cancer in mice. Int J Cancer 123: 951-957, 2008.

16. Sekine Y, Furuya Y, Nishii M, Koike H, Matsui H and Suzuki K: Simvastatin inhibits the proliferation of human prostate cancer PC-3 cells via down-regulation of the insulin-like growth factor 1 receptor. Biochem Biophys Res Commun 372: 356$361,2008$.

17. Sanchez CA, Rodriguez E, Varela E, et al: Statin-induced inhibition of MCF-7 breast cancer cell proliferation is related to cell cycle arrest and apoptotic and necrotic cell death mediated by an enhanced oxidative stress. Cancer Invest 26: 698-707, 2008.

18. Saito A, Saito N, Mol W, et al: Simvastatin inhibits growth via apoptosis and the induction of cell cycle arrest in human melanoma cells. Melanoma Res 18: 85-94, 2008.

19. Kulawiec M, Owens KM and Singh KK: Cancer cell mitochondria confer apoptosis resistance and promote metastasis. Cancer Biol Ther 8: 1378-1385, 2009.

20. Glinsky GV, Glinsky VV, Ivanova AB and Hueser CJ: Apoptosis and metastasis: increased apoptosis resistance of metastatic cancer cells is associated with the profound deficiency of apoptosis execution mechanisms. Cancer Lett 115: 185-193, 1997.

21. Herman-Antosiewicz A and Singh SV: Signal transduction pathways leading to cell cycle arrest and apoptosis induction in cancer cells by Allium vegetable-derived organosulfur compounds: a review. Mutat Res 555: 121-131, 2004.

22. Hindler K, Cleeland CS, Rivera E and Collard CD: The role of statins in cancer therapy. Oncologist 11: 306-315, 2006.

23. Cafforio P, Dammacco F, Gernone A and Silvestris F: Statins activate the mitochondrial pathway of apoptosis in human lymphoblasts and myeloma cells. Carcinogenesis 26: 883-891, 2005.

24. Aberg M, Wickstrom M and Siegbahn A: Simvastatin induces apoptosis in human breast cancer cells in a NFkappaBdependent manner and abolishes the anti-apoptotic signaling of TF/FVIIa and TF/FVIIa/FXa. Thromb Res 122: 191-202, 2008.

25. Li HY, Appelbaum FR, Willman CL, Zager RA and Banker DE: Cholesterol-modulating agents kill acute myeloid leukemia cells and sensitize them to therapeutics by blocking adaptive cholesterol responses. Blood 101: 3628-3634, 2003.

26. Zhuang L, Kim J, Adam RM, Solomon KR and Freeman MR: Cholesterol targeting alters lipid raft composition and cell survival in prostate cancer cells and xenografts. J Clin Invest 115: 959-968, 2005.

27. Gliemroth J, Zulewski H, Arnold H and Terzis AJ: Migration, proliferation, and invasion of human glioma cells following treatment with simvastatin. Neurosurg Rev 26: 117-124, 2003.

28. Paragh G, Kertai P, Kovacs P, Paragh G Jr, Fulop P and Foris G: HMG CoA reductase inhibitor fluvastatin arrests the development of implanted hepatocarcinoma in rats. Anticancer Res 23: 3949-3954, 2003. 
29. Taras D, Blanc JF, Rullier A, et al: Pravastatin reduces lung metastasis of rat hepatocellular carcinoma via a coordinated decrease of MMP expression and activity. J Hepatol 46: 69-76, 2007.

30. Kawata S, Kakimoto H, Ishiguro H, Yamasaki E, Inui $Y$ and Matsuzawa Y: Effect of pravastatin, a potent 3-hydroxy-3methylglutaryl-coenzyme A reductase inhibitor, on survival of AH130 hepatoma-bearing rats. Jpn J Cancer Res 83: 1120-1123, 1992.

31. Graf H, Jungst C, Straub G, et al: Chemoembolization combined with pravastatin improves survival in patients with hepatocellular carcinoma. Digestion 78: 34-38, 2008.

32. Kawata S, Yamasaki E, Nagase T, et al: Effect of pravastatin on survival in patients with advanced hepatocellular carcinoma. A randomized controlled trial. Br J Cancer 84: 886-891, 2001.

33. Lee J, Jung KH, Park YS, et al: Simvastatin plus irinotecan, 5-fluorouracil, and leucovorin (FOLFIRI) as first-line chemotherapy in metastatic colorectal patients: a multicenter phase II study. Cancer Chemother Pharmacol 64: 657-663, 2009.

34. Murray AW: Recycling the cell cycle: cyclins revisited. Cell 116: 221-234, 2004

35. Grana X and Reddy EP: Cell cycle control in mammalian cells: role of cyclins, cyclin dependent kinases (CDKs), growth suppressor genes and cyclin-dependent kinase inhibitors (CKIs). Oncogene 11: 211-219, 1995.
36. Pavletich NP: Mechanisms of cyclin-dependent kinase regulation: structures of Cdks, their cyclin activators, and Cip and INK4 inhibitors. J Mol Biol 287: 821-828, 1999.

37. Kastan MB, Canman CE and Leonard CJ: P53, cell cycle control and apoptosis: implications for cancer. Cancer Metastasis Rev 14: 3-15, 1995.

38. Molinari M: Cell cycle checkpoints and their inactivation in human cancer. Cell Prolif 33: 261-274, 2000.

39. Hoque A, Chen H and Xu XC: Statin induces apoptosis and cell growth arrest in prostate cancer cells. Cancer Epidemiol Biomarkers Prev 17: 88-94, 2008.

40. Denoyelle C, Albanese P, Uzan G, et al: Molecular mechanism of the anti-cancer activity of cerivastatin, an inhibitor of HMG$\mathrm{CoA}$ reductase, on aggressive human breast cancer cells. Cell Signal 15: 327-338, 2003.

41. Teoh N, Pyakurel P, Dan YY, et al: Induction of p53 Renders ATM-Deficient Mice Refractory to Hepatocarcinogenesis. Gastroenterology 138: 1155-1165, 2010.

42. Chan KC, Wang CJ, Ho HH, Chen HM and Huang CN: Simvastatin inhibits cell cycle progression in glucose-stimulated proliferation of aortic vascular smooth muscle cells by upregulating cyclin dependent kinase inhibitors and p53. Pharmacol Res 58: 247-256, 2008. 